\title{
Receptor screening resources on the Net
}

\author{
Robert S. Sikorski and Richard Peters
}

This month we sent out search tools on the Internet for resources that could be useful to scientists interested in developing drugs based on specific receptors. After reviewing over 600 netsites, we came up with our "best-of-the net" selections. They represent a sampling of the

Robert Sikorski is a Howard Hughes Medical Institute fellow at National Cancer Institute and Richard Peters is at the Department of Medicine, Masachusetts General Hospital

(rss@nchgr.nih.gov; and rpeters@vp3.med.harvard.edu; http://www.medsitenavigator.com). breath and depth of the material that exists on the Internet today. It was encouraging to see so many individual laboratories at both the university and in industry committing to the development of sophisticated WWW resources. In fact, most of the outstanding sites for receptor biologists are maintained by laboratories focusing on a particular class or family of receptors.

The netsite from Yale University (http://paella.med.yale.edu/cgi-bin/receptor top/DB_CGI.p/query?FORM\%3bHOME) is especially interesting because of their policy on the dissemination of unpublished data. In order to enhance their efforts to collect and share information on olfactory receptors, the webmasters at this location have instituted a policy whereby access to the site's private data is restricted to a select group of individuals who all agree to submit and share unpublished material. The public side of the site only shares published data. It will be interesting to see if this concept spreads to other biological databases as well.

As always, this column and its links can be found on the net at the Medsite Navigator (http://www.medsitenavigator.com) augmented with additional resources as they are found. We welcome your suggestions.

A sampler of products and services sites related to receptors

G protein-coupled receptor database http://receptor.mgh.harvard.edu/GCRDBHOME.html

Computational chemistry

http://mgddk1.niddk.nih.gov:8000/compchem.html

The thyroid hormone receptor resource

Olfactory receptor database

Chemical MIME type viewers

http://www.ch.ic.ac.uk/chemical_mime_first.html

Receptor binding assays on multiscreen glass fiber filter plates

US Patent Office

http://www.millipore.com:80/analytical/technote/ multiscreen/mm013.htm

http://www.uspto.gov

Pharmacology glossary

http://med-amsa.bu.edu:80/Pharmacology/

Programmed/glossary.html

3D searching with receptor-based queries http://www.ch.ic.ac.uk:80/ectoc/papers/guner/
This is about as close to complete coverage of one particular receptor class as you can get. In addition to the latest news on G-protein research, sequences, and meetings, the site is putting together a graphical map of the evolution of the subclasses.

This site is rather specific to one lab's interests at the $\mathrm{NIH}$, but it does illustrate how a mixture of graphics and text can be used on the WWW. It covers aspects of molecular modeling of $\mathrm{G}$ protein-coupled receptors.

A resource from Massachusetts General Hospital containing information on the thyroid hormone receptor family.

A database of the growing class of olfactory receptors and their biology from Yale University. There is a mix of public and private access to these resources.

In order to view the 3D chemical structures of molecules with a browser, a piece of software called a viewer is needed. This site explains how to find and set up a viewer for your operating system.

This site at Millipore discusses the details of doing receptor binding assays on glass fiber filters.

This site from the US government contains a wealth of information on patenting of materials and has a searchable database of patents.

This links to a rather impressive, hypertext glossary of terms and symbols used in pharmacology. It comes from Boston University.

This is an interesting site presenting information on the ability to search for molecules with similar chemical structures.

\section{PEOPLE}

ICN Pharmaceuticals (Costa Mesa, CA) has announced the appointment of Devron Averett as corporate senior vice president of research and development. Dr. Averett joins ICN from GlaxoWellcome, where he headed the department of molecular and cellular virology at GlaxoWellcome Research Laboratories.
Oxford Molecular Group (Campbell, CA), has announced the appointments of Frank $\mathrm{K}$. Brown as group product director and Mark Cortelyou as bioinformatics business development manager. Dr. Brown was previously senior manager of the GlaxoWellcome Research Institute Chemoinformatics Group. Mr. Cortelyou joins Oxford Molecular
Group from the Eastman Kodak Company's Scientific Imaging Division in Rochester, NY.

Mercator Genetics (Menlo Park, CA) has announced the promotion of Karen J. Brunke to vice president of clinical research. Previously, Dr. Brunke served as director of plant biotechnology at Sandoz Agro Inc. 